\title{
Explaining Cross-Country Differences in Attitudes towards Immigration in the EU-15
}

\author{
Malchow-Møller, Nikolaj; Munch, Jakob Roland; Schroll, Sanne; Rose Skaksen, Jan
}

Document Version

Final published version

Publication date:

2007

License

CC BY-NC-ND

Citation for published version (APA):

Malchow-Møller, N., Munch, J. R., Schroll, S., \& Rose Skaksen, J. (2007). Explaining Cross-Country Differences in Attitudes towards Immigration in the EU-15.

Link to publication in CBS Research Portal

\footnotetext{
General rights

Copyright and moral rights for the publications made accessible in the public portal are retained by the authors and/or other copyright owners and it is a condition of accessing publications that users recognise and abide by the legal requirements associated with these rights.

Take down policy

If you believe that this document breaches copyright please contact us (research.lib@cbs.dk) providing details, and we will remove access to the work immediately and investigate your claim.
}

Download date: 26. Apr. 2023 


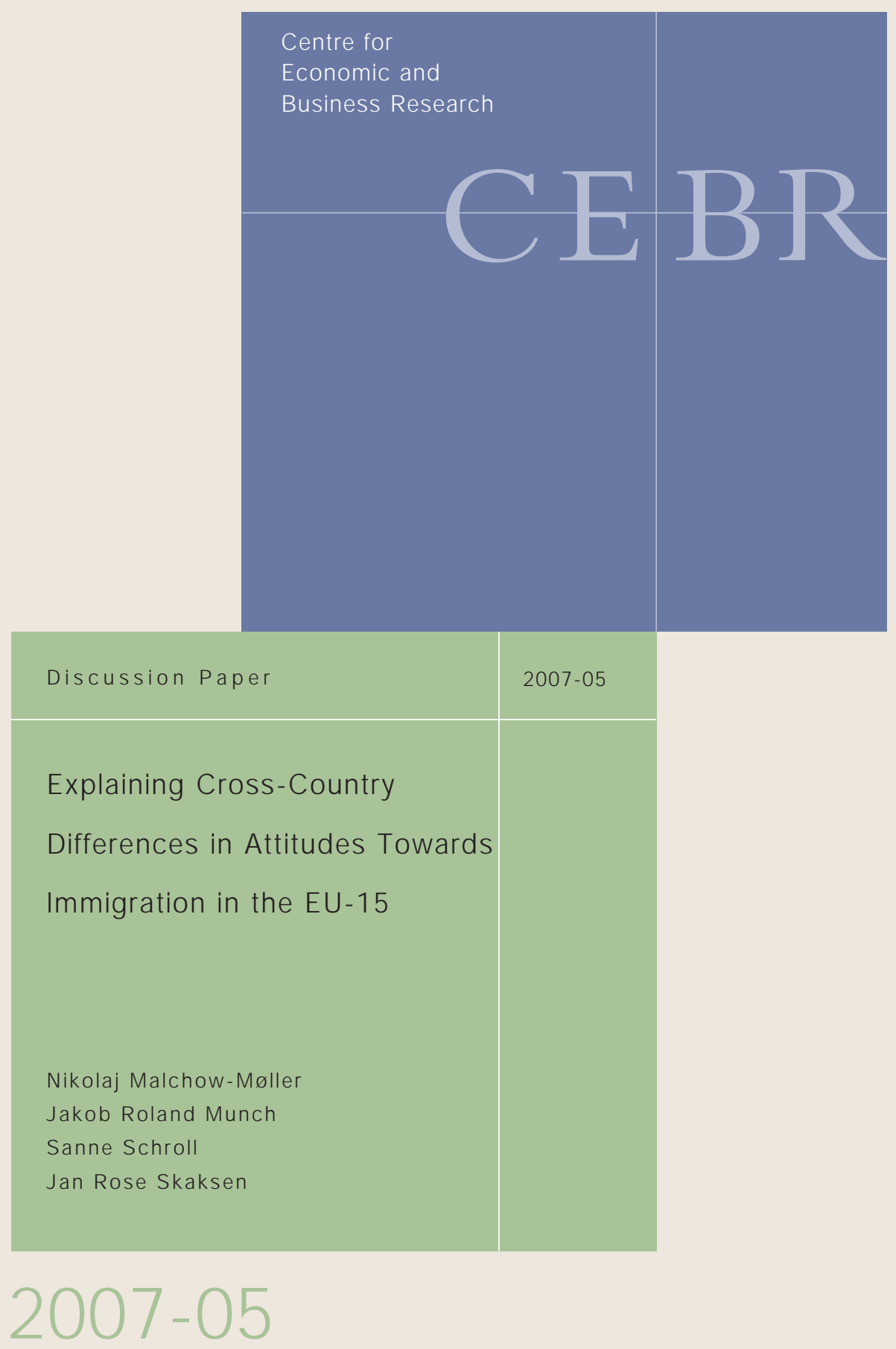




\title{
Explaining Cross-Country Differences in Attitudes towards Immigration in the EU-15. ${ }^{1}$
}

\author{
Nikolaj Malchow-Møller ${ }^{1,2}$, Jakob Roland Munch ${ }^{1,3}$, \\ SAnNe Schroll ${ }^{1,2}$ And Jan Rose SkaKsen ${ }^{1,4}$ \\ ${ }^{1}$ Centre for Economic and Business Research (CEBR) \\ ${ }^{2}$ University of Southern Denmark \\ ${ }^{3}$ University of Copenhagen \\ ${ }^{4}$ Copenhagen Business School
}

January 2007

\footnotetext{
${ }^{1}$ This paper is part of a joint project between CEBR and the Rockwool Foundation Research Unit. Financial support from the Rockwool Foundation is gratefully acknowledged. The authors wish to thank Vibeke Borchsenius and Jonas Helth Lønborg for excellent research assistance. Corresponding author: Jan Rose Skaksen, Copenhagen Business School, Porcelænshaven 16A, DK-2000 Frederiksberg, Denmark. e-mail: jrs.eco@cbs.dk; phone +45 38152582.
} 


\begin{abstract}
In this paper, we use data from the first two rounds of the European Social Survey to analyze the extent to which differences in average attitudes towards immigration across the EU-15 countries may be explained by differences in socioeconomic characteristics and individually perceived consequences of immigration, using an extension of a decomposition technique developed by Fairlie (2005). We find that despite the significant effects of socioeconomic characteristics on attitudes, differences in the distributions of these characteristics can only explain a modest share of the cross-country variation in average attitudes. A larger part can be explained by differences in perceived consequences of immigration, but the main part is still left unexplained. Apart from providing useful input for policy makers working in the area of immigration policy, this raises a number of questions for further research for which the ESS data can be successfully applied.
\end{abstract}

Keywords: Attitudes, Immigration, Cross-country differences

JEL Classification: F1, F22, J61 


\section{Introduction}

A number of recent studies have documented that attitudes towards immigration vary across countries; see, e.g., Mayda (2006), Card et al. (2005), Boeri and Brücker (2005), and Hainmueller and Hiscox (2005). In this paper, we use data from the first two rounds of the European Social Survey (ESS) to analyze the extent to which differences in average attitudes towards immigration across the EU-15 countries may be explained by differences in socioeconomic characteristics and individually perceived consequences of immigration. ${ }^{1}$ We do this by extending the decomposition technique developed by Fairlie (2005), which in turn builds on the well-known Blinder-Oaxaca decomposition technique (Blinder, (1973); Oaxaca, (1973)).

A large number of empirical studies have previously explained attitudes towards immigration using socioeconomic characteristics; see, e.g., Scheve and Slaughter (2001) and Mayda (2006). A smaller number of studies have also included perceived consequences of immigration among the explanatory variables, see, e.g., Dustmann and Preston (2004), Card et al. (2005) and Malchow-Møller et al. (2006). However, it has not yet been analyzed whether these characteristics in fact can explain observed cross-country differences in average attitudes towards immigration. This is what the current paper attempts.

Why is this relevant? First, in the academic literature it has been discussed whether the EU countries should optimally harmonize their immigration policies; see, e.g., Wellisch and Wildasin (1996), Casella (2005), and Boeri and Brücker (2005). Thus, it has recently been argued by, e.g., Boeri and Brücker (2005) that with unilateral immigration policies, we may end up observing a suboptimal "race to the top" where countries compete to introduce the most restrictive rules. A harmonizations of EU immigration policies could rectify this problem.

Second, the EU countries have already taken some steps towards a harmonization of their immigration policies. Since May 2004, the Council can take decisions by "qualified majority" vote in questions regarding immigration policy and already in 1999, the European Council agreed that the questions concerning asylum and immigration demands that a common EU policy is designed.

Thus, there is a growing awareness both among politicians and academics that at least some harmonization of immigration policies among the EU

\footnotetext{
${ }^{1}$ The EU-15 countries or the "old" EU countries are the members of EU before the enlargement in 2004. These include: Germany, France, Italy, Belgium, The Netherlands, Luxembourg, Denmark, Ireland, UK, Greece, Spain, Portugal, Austria Finland, and Sweden.
} 
countries is required. But the feasibility of such policies are often influenced by people's attitudes. At least from a political economy perspective, we may expect such attitudes to play a role, since politicians are often concerned about getting reelected, and hence will be interested in the feelings of the voters towards immigrants (Bauer et al., 2000).

In light of this, a better understanding of what drives cross-country differences in attitudes could provide useful input for the process of policy harmonization within the EU. It may, for instance, provide guidance for how to compensate the most sceptical countries/individuals. If, for example, socioeconomic differences explain a large part of the differences, compensating measures or special attention should be directed towards the most sceptical socioeconomic groups rather than sceptical countries. If instead perceived consequences of immigration explain cross-country differences, it may be crucial for policy makers to address these concerns (instead of specific groups) explicitly in a common immigration policy

The ESS data are well-suited for a cross-country analysis of attitudes, as they not only contain information about attitudes towards immigration and perceived consequences of immigration for all EU-15 countries. The questions have also been designed to ensure that they are understood in the same way across countries.

We focus our analysis on attitudes towards immigration from poor countries as most of the debate on immigration policies in Europe concerns immigration from such countries. However, we distinguish explicitly between attitudes towards immigration from poor European and poor non-European countries, respectively, as these attitudes are relevant for two different policy areas. While the former is relevant for traditional immigration policies, attitudes towards immigration from poor European countries may also have implications for future enlargements of the EU as well as the potential harmonization of the transitional arrangements put in place in connection with such enlargements.

The first step of the empirical analysis is to estimate logit models of attitudes towards different types of immigration. In these regressions, we include the usual socioeconomic explanatory variables from the existing literature. In line with some more recent studies, we also include a number of variables capturing perceived consequences of immigration. The second step is to use the estimated logit models to decompose the average differences across countries into a part due to observable characteristics of the individuals (socioeconomic characteristics and perceptions) and a part due to different effects of these characteristics across countries. In doing this we extend a technique developed by Fairlie (2005) for decomposing differences in averages of binary outcomes between two groups, e.g., gender and racial 
gaps in college attendance. In our case, we compare 15 groups (countries), and we therefore develop a decomposition where we compare each country to the mean of all other countries - including the country itself.

In line with previous studies, we document that there is considerable variation in average attitudes across countries. Furthermore, we find that attitudes also vary substantially with socioeconomic characteristics. Poor or unemployed people or people with only primary education tend to be more negative towards immigration whereas people living in urban areas, with an immigrant background, or with tertiary education tend to be the most positive towards immigration. These findings are also well in line with those of the existing literature. Furthermore, those who perceive that immigrants will affect labour market options of natives negatively or strain the public budget are also more negative towards immigration.

Despite the significant effects of socioeconomic characteristics on attitudes, differences in the distributions of these characteristics across countries are only able to explain a modest share of the cross-country variation in average attitudes. A larger part can be explained by differences in perceived consequences of immigration, but the main part is still left unexplained.

Apart from providing useful input for policy makers working in the area of immigration policy, this raises a number of questions for further research for which the ESS data can be successfully applied: First, what underlies the large unexplained cross-country differences? Second, why do perceived consequences vary across individuals and countries? We shall return to these questions at the end of the paper.

The rest of the paper is structured as follows. In Section 2, we present the ESS data. Section 3 outlines the empirical approach, while Sections 4 and 5 contain the empirical analysis. In Section 4, we explain attitudes towards immigration on the basis of socioeconomic and perception variables, while we decompose country differences in Section 5. Finally, Section 6 concludes.

\section{ESS Data}

We use data from the first two rounds of the European Social Survey (ESS), 2002/3 and 2004/5, which cover 22 and 26 European and associated countries, respectively. However, in this paper, we only use data for the EU-15 countries. The ESS interviews around 2,000 randomly selected persons of age 15 or above in each country. ${ }^{2}$ ESS $2002 / 3$ contains a special module with

\footnotetext{
${ }^{2}$ There are minor deviations from random sampling in some countries. We correct for this non-random sampling within countries as well as differences in sample/population ratios across countries in the analyses to follow.
} 
a number of questions about people's attitudes towards immigration. This module is unique in the sense that it also contains questions about the respondents' perceptions of the (economic) implications of immigration. Furthermore, both rounds of the ESS hold information about people's educational background, labour market association and a number of other background characteristics.

The questions in the ESS have been carefully designed to ensure that they are understood in the same way across countries. This is important because the European countries are very diverse with respect to culture, language, immigration history and immigration laws. For example, the word "immigrant" has been avoided in the questionnaire because this word has different connotations in different countries. Instead, the questionnaire refers to "people who come to live in the country". 3 Furthermore, special attention has been given to ensure that the questions about the respondents' preferences for the restrictiveness of the immigration policy are understood in the same way across countries. This makes the ESS data particularly useful for a cross-country comparison of attitudes towards immigration as in the present paper. We refer to Card et al. (2005) for more details on the design of the questionnaire.

In the empirical analyses below, we will use a number of variables to capture different aspects of individual attitudes towards immigration. The respondents in ESS 2002/3 have all been asked separately about their attitudes towards immigration from rich and poor countries, within and outside Europe, respectively, whereas the respondents in ESS 2004/5 have only been asked about their attitudes towards immigration from poorer countries outside Europe. The possible answers to these five questions were: "allow many to come and live here", "allow some", "allow a few", and "allow none". From these questions, we construct four attitude variables. First, the variable, $A_{\text {poor_euro }}$, is a dummy variable taking the value 1 if the answer to the question about immigrants from poor European countries in ESS 2002/3 was either "allow a few" or "allow none". $A_{\text {poor_noneuro_2002 }}$ and $A_{\text {poor_noneuro_2 } 2004}$ are defined similarly from the questions about poor non-European immigrants in ESS 2002/3 and ESS 2004/5, respectively. Finally, $A_{\text {relative euro }}$ is defined as a dummy variable taking the value one if the respondent in ESS 2002/3 has expressed a (strictly) less positive attitude towards immigrants from poor European countries than from rich European countries. This relative measure of attitudes is included because in relation to EU enlargements, it can be argued that it may be more relevant to consider attitudes towards immigrants from new potential members (poor European countries) rela-

\footnotetext{
${ }^{3}$ We shall use the word immigrant in this paper to ease exposition.
} 
tive to attitudes towards immigrants from existing members (rich European countries).

Table 2.1 presents country and EU-15 averages of the four attitude measures. At least three points can be observed from the Table. First, EU-15 citizens are generally more negative towards immigration from poor nonEuropean countries than from poor European countries. Second, attitudes towards immigration from poor non-European countries became more negative from the first to the second round of the ESS. Third, EU-15 citizens are generally more positive towards immigration from rich (European) than poor (European) countries.

\section{[Insert Table 2.1 around here]}

Table 2.1 also shows that there is considerable variation across countries, with Greece and Sweden as the two extremes. In Greece, around 85\% oppose further immigration from poor countries (European and non-European), while only around $15 \%$ express similar attitudes in Sweden. With respect to the relative measure, Denmark and Greece exhibit the highest averages, but for different "reasons". While Greeks are more critical of immigrants from poor countries than the average EU-15 citizen, the average Dane is somewhat more positive towards immigration from rich countries.

In the analyses to follow, we use a number of individual characteristics to explain the attitudes towards immigration. In particular, we use: age (and age squared), gender, living in an urban or a rural area, immigrant background (including both first and second generation immigrants), educational level (primary, secondary or tertiary), unemployment (a dummy variable indicating that the individual or his/her partner is unemployed), self employment (a dummy variable indicating whether the individual is self-employed), recipient of social benefits (a dummy variable indicating that the individual is retired, permanently sick or disabled, and therefore a potential recipient of social benefits), and poorest quartile (a dummy for the individual belonging to the poorest quartile in the EU-15 as measured by total household income). Summary statistics of these variables can be found in Table 2.2 below.

We also construct seven perception variables, where five of these concern possible economic consequences, while the last two concern consequences for culture and crime, respectively. The perception variables are constructed as dummy variables each taking the value 1 if the respondent agreed with the corresponding statement among the following: "Average wages are generally brought down by immigrants"; "Immigrants harm economic prospects of the poor more than the rich"; "Immigrants help to fill jobs where there are shortages of workers"; "Immigrants take jobs away in country"; "Taxes and 
services: immigrants take more out than they put in"; "Country's cultural life is undermined by immigrants"; and "Immigrants make country's crime problems worse". With respect to the first three statements, the respondents could choose between 5 answers from "Agree strongly" to "Disagree strongly", while for the last four statements, the respondents could choose their degree of "agreement" on a scale from 0 to 10 . We assign the value one to the corresponding dummy variable if the respondent has chosen an answer above the middle (neutral) category.

\section{[Insert Table 2.2 around here]}

Table 2.2 provides an overview of the distribution of the socioeconomic characteristics and perceptions across the EU-15 countries. We observe that there are substantial differences across countries with respect to both socioeconomic characteristics and perceptions. As an example, the proportion of people with tertiary education varies from $7.0 \%$ in Italy to $32.2 \%$ in Sweden. Another example is that in Sweden only $15 \%$ agree that average wages are generally being brought down by immigrants, while the corresponding number in Greece is almost $82 \%$. Thus, there appears to be considerable room for explaining differences in average attitudes across countries by both differences in socioeconomic characteristics and perceived consequences.

\section{The Empirical Approach}

Table 2.1 revealed considerable variation in average attitudes towards immigration across the EU countries. There can be two different reasons for this. First, differences may simply reflect different distributions of explanatory factors across countries. That is, the positive attitudes of Swedes may just reflect a different socioeconomic composition of the Swedish people, e.g., that Swedes are more educated and that educated individuals are generally more positive towards immigration. Alternatively, differences may reflect that different factors determine attitudes in the different countries. The main purpose of this paper is to determine the relative importance of these reasons. In other words, when we take out that part of the differences which can be explained by a different distribution of observable factors (explanatory variables), how large are the resulting differences?

In the existing literature, individual attitudes towards immigration have been explained by socioeconomic characteristics, see, e.g., Scheve and Slaughter (2001) and Mayda (2006). A particular focus in this literature has been on the role played by education, where most studies find that the less educated are considerably more opposed to immigration. A smaller number of 
more recent studies have included individually perceived consequences of immigration - mostly economic but also cultural/social consequences - among the explanatory variables; see Dustmann and Preston (2004), Hainmueller and Hiscox (2005), Card et al. (2005), and Malchow-Møller et al. (2006).

The empirical analysis in this paper proceeds in two steps. In Section 4, we estimate logit models for each of the four attitude variables, including the usual socioeconomic explanatory variables among the regressors. In some of the regressions, we also include the dummies capturing individually perceived consequences of immigration. In Section 5, we then decompose the differences in average country attitudes into: i) a part that is due to different observable characteristics of individuals across countries, i.e., different distributions across countries of the explanatory variables used in the regressions in Section 4; and ii) a part that is due to different effects of these characteristics, i.e., different "coefficients" in the estimations, including differences in unobservable factors.

The technique used for this purpose was originally developed for linear models by Blinder (1973) and Oaxaca (1973), and has recently been extended to logit and probit models by Fairlie (2005). However, since Fairlie (2005) is comparing the average predicted probabilities of only two groups, e.g., unemployment incidence of blacks and whites, we extend his method to allow for more than two groups in the comparison. More precisely, we compare averages of 15 groups (countries), and we therefore focus on the difference between each country's average and the average of all countries (including the country itself).

After estimating a logit model with country specific intercepts and slopes, the difference between the average attitude in country $i, \bar{A}_{i}$, and the average EU attitude, $\bar{A}_{E U}$, can (for each of the four attitude variables) be expressed as:

$$
\bar{A}_{i}-\bar{A}_{E U}=\sum_{j} \frac{v_{i j} F\left(X_{i j}, \hat{\beta}\right)}{\Sigma_{j} v_{i j}}-\sum_{i j} \frac{v_{i j} F\left(X_{i j}, \hat{\beta}\right)}{\Sigma_{i j} v_{i j}}
$$

where $X_{i j}$ is a vector of socioeconomic characteristics and perceptions of individual $j$ in country $i, v_{i j}$ is the sampling weight attached to individual $j$ in country $i, \hat{\beta}$ is the estimated parameter vector in the model allowing for country-specific intercepts and slopes, and $F\left(X_{i j}, \hat{\beta}\right)$ is thus the predicted attitude (probability) of individual $i$ in country $j$. The first term on the right hand side in (1) is therefore the average predicted probability of being against immigration for the individuals in country $i$, while the second term is the average predicted probability for the entire EU-15. The equality in (1) holds since a property of the logit model is that the average predicted 
attitude equals the actual proportion against immigration. If we had used the probit model instead, this would not have been the case.

Now, building on Fairlie (2005), we can alternatively express the difference in (1) as:

$$
\begin{aligned}
\bar{A}_{i}-\bar{A}_{E U}= & \sum_{j} \frac{v_{i j} F\left(X_{i j}, \bar{\beta}\right)}{\Sigma_{j} v_{i j}}-\sum_{i j} \frac{v_{i j} F\left(X_{i j}, \hat{\beta}\right)}{\Sigma_{i j} v_{i j}} \\
& +\sum_{j} \frac{v_{i j} F\left(X_{i j}, \hat{\beta}\right)}{\Sigma_{j} v_{i j}}-\sum_{j} \frac{v_{i j} F\left(X_{i j}, \bar{\beta}\right)}{\Sigma_{j} v_{i j}}
\end{aligned}
$$

where $\bar{\beta}$ is a vector of EU averages of the estimated coefficients, with the $s^{\prime}$ th element of this vector given by:

$$
\bar{\beta}_{s}=\frac{\sum_{i} v_{i} \hat{\beta}_{s, i}}{\sum_{i} v_{i}}
$$

where $\hat{\beta}_{s, i}$ is the coefficient for country $i$ on the $s^{\prime}$ th explanatory variable, and $v_{i}$ is the weight for country $i{ }^{4}$

In equation (2), the first two terms on the right hand side express the difference between country $i$ and the EU average that can be ascribed to differences in the distributions of the explanatory variables. The last two terms on the right hand side express the part of the difference between country $i$ and the EU average which is due to different coefficients. These terms also capture the part of the difference which is due to differences in unobservable factors (different intercepts). ${ }^{5}$

\section{Explaining Attitudes towards Immigration}

In Table 4.1 we present estimation results for the four different attitude measures. In the first four columns, only socioeconomic explanatory variables are included on the right hand side whereas perceptions are added in the last three columns. Note that perception variables are only available for the first round of the ESS.

\footnotetext{
${ }^{4}$ Note that since the model is estimated by omitting coefficients for a reference country, $\hat{\beta}_{s, i}$ is given by the overall coefficient plus the coefficient for country $i$. Instead of using these average coefficients, we could instead estimate the model without country specific coefficients and use the estimated coefficients from this "pooled" regression as the EU average coefficients.

${ }^{5}$ As argued by Fairlie (2005), we cannot distinguish between the effects of different intercepts across countries and the effects of different slopes.
} 
The models were estimated both with and without country-specific coefficients. For the decomposition in the following section, we rely on estimation results for the "full" model with both country-specific intercepts and slopes. However, to ease exposition and facilitate the review of the general (EUwide) effects of the different explanatory variables, Table 4.1 presents results from the estimation with common slopes, but country-specific intercepts. ${ }^{6}$

\section{[Insert Table 4.1 around here]}

From the regressions where only socioeconomic variables are included, it is seen that people living in urban areas, people with immigrant background and people with tertiary education tend to be more positive towards immigration from poor countries (European or non-European), whereas poor or unemployed people and people with only primary education tend to be more negative towards immigration.

The estimated coefficients for the socioeconomic variables are fairly robust to the inclusion of perception variables, as seen in the last three columns of the Table. The interesting part of these new regressions is thus the coefficients to the perception variables. All the estimated coefficients are statistically significant with the expected signs. Thus, only the dummy referring to the statement, "Immigrants help to fill jobs where there are shortages of workers", has a negative coefficient. That is, people agreeing that "immigrants help to fill jobs, where there are shortages of workers" have a tendency to be more positive towards immigration, whereas people agreeing that "average wages are generally brought down by immigrants" or agreeing with one of the other five perceptions tend to be more negative towards immigration from poor countries, both European and non-European.

These results are in accordance with former results presented in the literature. The result that less educated are more negative towards immigration has also been found by, e.g., Scheve and Slaughter (2001), Mayda (2006), Hainmueller and Hiscox (2005), and Card et. al (2005). That older people tend to be more negative towards immigration is also confirmed by several other studies, e.g. Mayda (2006), Hainmueller and Hiscox (2006), Dustmann and Preston (2004), and Malchow-Møller et al. (2006). Males being more positive towards immigration is also reported by Mayda (2006), and she also confirms that people with low incomes tend to be more negative towards immigration. Furthermore, both Mayda (2006) and Scheve and Slaughter (2001) find that immigrants and descendants of immigrants tend to be more in favour of immigration. Finally, Card et. al (2005) also confirm the finding that people believing that immigration is good for the economy tend

\footnotetext{
${ }^{6}$ Most results do not change qualitatively with the exclusion of country-specific slopes.
} 
to be more positive towards immigrants. On the other hand Dustmann and Preston (2004) find that it is less likely that unemployed people are in favour of a more restrictive immigration policy for immigrants from poorer non-European countries, where we find that unemployed are more against immigration from poorer countries (both European and non-European).

Now, turn to the results for the relative attitude measure. The effects of the perception variables are qualitatively the same, which means that if you perceive immigration to have negative consequences for, e.g., domestic wages, you are both more opposed to immigration in general and towards immigration from poor countries in particular. However, when it comes to the effects of the socioeconomic variables, there are some differences between the relative attitude measure and the absolute measures. Thus, while males are generally found to be more positive towards immigration in an absolute sense, they tend to be relatively more negative towards immigration from poor European countries compared to immigration from rich European countries. Or, put differently, they tend to be relatively more positive towards immigration from rich countries. The variables, urban and immigrant, reveal the same differences between the relative attitude measure and the absolute attitude measures.

Furthermore, while individuals with only a primary education are found to be more negative towards immigration in an absolute sense than individuals with secondary education, they tend, somewhat surprisingly, to be relatively more positive towards immigration from poor countries compared to immigration from rich countries. Self-employed are also relatively more in favour of immigration from poor countries, although they were not found to have significant effects on the absolute measures. Perhaps, they benefit in particular from low-skilled labour inflow. Finally, while individuals from poor households are generally more opposed to immigration, they do not show particular preferences for rich immigrants compared to poor immigrants.

Note that we should be careful with the causal interpretation of the coefficients on the perception variables. First, it could be that there are some unobserved individual factors that both cause negative attitudes towards immigration and at the same time influence people's perceptions of the consequences of immigration, e.g., fear of foreign people or foreign lifestyle. Second, people could be trying to rationalize their negative attitudes towards immigration. That is, if the respondent has first answered that only "a few" or "none" immigrants should be allowed into the country, then (s)he might try to justify this answer by also answering that (s)he expects immigration to have negative consequences for natives in the labour market. This type of endogeneity bias is referred to as justification bias in the literature. 
To determine the importance of the first endogeneity problem, we have also run the regressions with the inclusion of two extra independent variables that should capture the fear of foreign people or culture. The two variables measure the extent to which the respondent will be negative towards having a person with another ethnical background than the majority of the population in the country as his/her boss or as married to a close relative. Both of these variables have a significantly positive effect on all four attitude measures, but when they are included in the regressions, the coefficients for the perception variables are only slightly affected. We take this as an indication that problems with this type of endogeneity are not substantial.

If, on the other hand, justification bias is a problem, we should observe it for all groups. However, in a recent paper, Malchow-Møller et al. (2006), we find that even though all people perceiving immigration to have negative consequences tend to be more negative towards immigration, the people being hurt personally by these consequences have the most negative attitudes. Thus, if a respondent agrees that immigrants take jobs away, then the probability that (s)he will be against more immigration is higher, but if, in addition, (s)he is out of work, (s)he is likely to be even more against immigration. This shows that economic self-interest matters when attitudes towards migration are formed and - more relevant for the endogeneity problem discussed here - it indicates that the perception variables capture what they are supposed to. However it is not possible to completely exclude the possibility of justification bias, and this should be taken into account in the following.

\section{$5 \quad$ Explaining Differences between Countries}

The question we set out to answer in this section is: How much of the deviation between the average attitude of country $i$ citizens and that of EU15 citizens can be explained by a different distribution of the observable characteristics (socioeconomic and perceptions) in country $i$ compared to the EU-15 as a whole?

Table 5.1 contains decompositions for each of the four attitude measures. ${ }^{7}$ Decompositions are made both when using only the socioeconomic variables, and when we also include the perception variables. The Table is constructed as follows: Consider part A where the dependent variable is the measure for

\footnotetext{
${ }^{7}$ The estimates of the full model with country-specific intercepts and slopes which underlie these decompositions are available upon request from the authors. The joint significance of the country-specific coefficients was tested (and confirmed) by use of a Wald test.
} 
attitudes towards immigrants from poorer European countries. In the first column, the total deviation for each country from the EU average is listed. As an example, for Greece, the total deviation is 0.4076, meaning that the probability of being against immigration is $40 \%$ higher in Greece than in the EU-15 in general. The next two columns show the decomposition when we control for socioeconomic variables alone. It appears that 0.0302 of the total deviation (7.4 percent) is due to differences in the socioeconomic variables while the rest is due to differences in the coefficients including the countrydummies (the unobservables). Moving along in the Table, the next two columns show the decomposition controlling for only perception variables. These variables explain more than half of the total deviation for Greece (0.2207), while the rest (0.1870) is explained by the coefficients. Finally, in the last two columns, we control for both socioeconomic variables and perceptions. Together, the distributions of these two groups of variables explain 54.6 percent of the total deviation.

Note that since we measure the total deviation as the difference between the average of country $i$ and the EU-15 average, deviations are negative for some countries. For, e.g., Sweden, the total deviation is -0.2950 , which means that in Sweden, there is a lower probability of being against immigration compared to the average in the EU-15. When we control for socioeconomic variables, -0.0243 of this is explained by differences in the distributions of these variables whereas the rest is due to differences in the coefficients. Differences in perceptions, on the other hand, can explain 0.1130 of the total deviation and together both types of variables explain 0.1136 of the total deviation.

Hence, both Sweden and Greece get closer to the EU-15 average when controlling for socioeconomic and, especially, perception variables. Other countries get further away from the EU-15 average. This is the case for, e.g., Luxembourg and the Netherlands. In fact, the distance from the EU-15 average is larger for about half of the countries after the decomposition than before.

\section{[Insert Table 5.1 around here]}

The decomposition for the second attitude measure (part B of the Table) shows almost the same picture. Luxembourg, in particular, gets further and further away from the EU-15 average as we control for first socioeconomic and then perception variables. On the other hand, Portugal deviates markedly from the EU-15 average before the decomposition, but then moves closer when we control for the different variables. For the third dependent variable (part $\mathrm{C}$ of the Table), which measures attitudes towards poor non- 
European countries in 2004/5, the decomposition causes most countries to move further away from the EU-15 average after controlling for the socioeconomic variables, which are the only variables available for this regression. For the relative attitude variable (part D of the Table), absolute deviations are smaller, but the picture from the decomposition is the same.

Now, taken together, do country averages get closer together when controlling for socioeconomic differences and perceptions? This can be seen by considering the standard deviations reported at the bottom of Table 5.1. The standard deviation below the third column, for example, reports the standard deviation of the differences remaining after controlling for socioeconomic characteristics. It is clear that although several of the countries move further away from the EU average, overall the standard deviation is reduced when controlling for observable characteristics. Controlling for socioeconomic differences reduces the standard deviation by 1-6\% while controlling for perceptions reduces the standard deviation by around $25 \%$ for the first two measures and by $15 \%$ for the relative attitude measure.

Thus, although socioeconomic characteristics are important determinants of attitudes towards immigration, differences in the distributions of these characteristics can only explain a minor share of the cross-country differences in average attitudes. As an example, while education is important for the individual attitude towards immigration, differences in educational levels across countries cannot explain why some countries appear more hostile than others towards further immigration. Different perceptions, on the other hand, may explain a significant share of the cross-country differences, but the main share is left unexplained. These results are potentially interesting in light of the recent harmonization discussions and efforts in relation to EU immigration policies. While measures targeted at certain socioeconomic groups are unlikely to mitigate country differences in attitudes to a large extent, it may be crucial for politicians to address the concerns related to the perception variables in a common EU immigration policy. Furthermore, it raises several perspectives for future research as discussed below.

\section{Conclusion}

This paper has documented that attitudes towards further immigration either European (EU enlargements) or non-European - vary considerably across countries. Despite the fact that socioeconomic characteristics are important determinants of attitudes - and have been used extensively in the existing literature in modelling attitudes - they can only explain a modest share of the cross-country differences in average attitudes towards immi- 
gration. A much larger share can be explained by differences in perceived consequences of immigration, but the main share still remains unexplained.

While contributing to a better understanding of the roots of cross-country differences, the results also have immediate implications for policy makers if they are to ensure that a common immigration policy receives widespread acceptance. As socioeconomic differences cannot explain much of the differences, addressing compensating measures or special attention towards the most sceptical socioeconomic groups will not resolve country differences. Instead, as perceived consequences can explain much more of the cross-country differences, it may be crucial for policy makers to address these concerns explicitly in a common immigration policy. As substantial cross-country differences prevail after controlling for differences in socioeconomic characteristics (the usual suspects) and perceived consequences of immigration, specific country considerations may also have to be incorporated in a common immigration policy for the EU countries.

The findings in this paper also raise a number of questions for future research. First, why do perceived consequences vary across individuals and countries? Second, what underlies the large unexplained cross-country differences? The answers to these questions may be closely related, and some work has already been initiated with the aim of understanding cross-country differences in attitudes towards immigration. Mayda (2006) has found that the cross-country differences may reflect differences in the skill composition of natives relative to immigrants with more skill-intensive countries being more positive towards (low-skilled) immigration. Boeri and Brücker (2005) find that countries with more generous social welfare systems and more rigid wage setting institutions tend to be more negative towards immigration. Finally, Card et al. (2005) suggest that differences may be due to several factors, including migration policy, migration experiences, and current state of the economy. The relative importance of these different hypotheses in explaining remaining cross-country differences should be explored in future work, possibly combining ESS data with data on country-level information about migration composition, history, and institutions. 


\section{References}

[1] Bauer, T., M. Lofstrom and K. F. Zimmermann (2000): "Immigration Policy, Assimilation of Immigrants, and Natives' Sentiments Towards Immigrants: Evidence from 12 OECD Countries", Swedish Economic Policy Review, 7, 11-53.

[2] Blinder, A. S. (1973): "Wage Discrimination: Reduced Form and Structural Estimates", Journal of Human Resources, 8, 436-455.

[3] Boeri, T. and H. Brücker (2005): "Why are Europeans so Tough on Migrants?", Economic Policy, 20 , 629-703.

[4] Casella, A. (2005): "Redistribution Policy: A European Model", Journal of Public Economics, 89, 1305-1331.

[5] Card, D., C. Dustmann and I. Preston (2005): "Understanding Attitudes to Immigration: The Migration and Minority Module of the first European Social Survey", CReAM Discussion Paper No. 03/05.

[6] Dustmann, C. and I. Preston (2004): "Racial and Economic Factors in Attitudes to Immigration", CReAM Discussion Paper No. 01/04.

[7] Fairlie, R. W. (2005): "An Extension of the Blinder-Oaxaca Decomposition Technique to Logit and Probit Models", Journal of Economic and Social Measurement, 30, 305-316.

[8] Hainmueller, J. and M.J. Hiscox (2005): "Educated Preferences: Explaining Attitudes Towards Immigration in Europe", Forthcoming in International Organization.

[9] Malchow-Møller, N, J.R. Munch, S. Schroll and J.R. Skaksen (2006): "Attitudes towards Immigration - Does Economic Self-Interest Matter?", CEBR Discussion Paper 2006-11, www.cebr.dk.

[10] Mayda, A. M. (2006): "Who is Against Immigration? A Cross-Country Investigation of Individual Attitudes towards Immigrants", Review of Economics and Statistics, 88, 510-533.

[11] Oaxaca, R. (1973): "Male-Female Wage Differentials in Urban Labor Markets", International Economic Review, 14, 693-709.

[12] Scheve, K. F. and M. J. Slaughter (2001): "Labor Market Competition and Individual Preferences over Immigration Policy", Review of Economics and Statistics, 133-145. 
[13] Wellisch, D. and D.E. Wildasin (1996): "Decentralized Income Redistribution and Immigration", European Economic Review, 40, 187-217. 
Table 2.1: Average attitudes towards immigration

\begin{tabular}{|l|r|r|r|r|}
\hline & $A_{\text {poor euro }}$ & $A_{\text {poor noneuro 2002 }}$ & $A_{\text {poor noneuro 2004 }}$ & $A_{\text {relative euro }}$ \\
\hline AT & 0.6325 & 0.673 & 0.5203 & 0.1541 \\
BE & 0.3955 & 0.451 & 0.5107 & 0.1702 \\
DE & 0.3728 & 0.424 & 0.5608 & 0.1795 \\
DK & 0.4581 & 0.560 & 0.6080 & 0.2674 \\
ES & 0.5084 & 0.528 & 0.4665 & 0.1303 \\
FI & 0.5837 & 0.642 & 0.6839 & 0.1928 \\
FR & 0.4275 & 0.490 & 0.5394 & 0.1483 \\
GB & 0.4777 & 0.525 & 0.5080 & 0.1644 \\
GR & 0.8414 & 0.863 & 0.8224 & 0.2518 \\
IE & 0.3252 & 0.373 & 0.3626 & 0.1387 \\
IT & 0.3506 & 0.386 & 0.0000 & 0.1915 \\
LU & 0.4988 & 0.539 & 0.5222 & 0.1017 \\
NL & 0.4249 & 0.450 & 0.4895 & 0.1016 \\
PT & 0.6301 & 0.648 & 0.7042 & 0.1248 \\
SE & 0.1385 & 0.160 & 0.1959 & 0.0845 \\
\hline EU & 0.4335 & 0.478 & 0.5324 & 0.1597 \\
\hline
\end{tabular}




\begin{tabular}{|c|c|c|c|c|c|c|c|c|c|c|c|c|c|c|c|c|}
\hline & & \begin{tabular}{|l|} 
AT \\
\end{tabular} & BE & \begin{tabular}{|l|}
$\mathrm{DE}$ \\
\end{tabular} & DK & ES & FI & FR & GB & \begin{tabular}{|l|} 
GR \\
\end{tabular} & IE & IT & LU & $\mathrm{NL}$ & \begin{tabular}{|l|} 
PT \\
\end{tabular} & SE \\
\hline \multirow{11}{*}{ 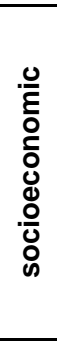 } & age & \begin{tabular}{|l|}
44.613 \\
\end{tabular} & \begin{tabular}{|r|}
45.664 \\
\end{tabular} & \begin{tabular}{|r|}
48.263 \\
\end{tabular} & 48.134 & \begin{tabular}{|l|l|}
420.120 \\
\end{tabular} & \begin{tabular}{|l|}
48.870 \\
\end{tabular} & \begin{tabular}{|l|}
45.854 \\
\end{tabular} & \begin{tabular}{|l|}
46.323 \\
\end{tabular} & \begin{tabular}{|r|}
48.052 \\
\end{tabular} & 45.802 & \begin{tabular}{|r|}
45.607 \\
\end{tabular} & \begin{tabular}{|l|}
42.686 \\
\end{tabular} & \begin{tabular}{|l|}
47.866 \\
\end{tabular} & \begin{tabular}{|l|l|}
5 & 47.463 \\
\end{tabular} & 48.373 \\
\hline & \begin{tabular}{|l|} 
age squared \\
\end{tabular} & 2,216 & 2,366 & 2,582 & 2,567 & 2,426 & 2,654 & 2,382 & 2,426 & 2,601 & 2,352 & 2,301 & 2,065 & 2,517 & 2,546 & 2,620 \\
\hline & male & 0.468 & 0.513 & 0.481 & 0.522 & 0.507 & 0.489 & 0.485 & 0.500 & 0.445 & 0.451 & 0.499 & 0.559 & 0.455 & 0.425 & 0.531 \\
\hline & \begin{tabular}{|l|} 
urban \\
\end{tabular} & 0.300 & 0.258 & 0.332 & 0.377 & 0.300 & 0.266 & 0.321 & 0.300 & 0.526 & 0.330 & 0.117 & 0.206 & 0.282 & 0.349 & 0.327 \\
\hline & \begin{tabular}{|l} 
immigrant \\
\end{tabular} & 0.168 & 0.172 & 0.152 & 0.095 & 0.085 & 0.043 & 0.197 & 0.162 & 0.174 & 0.097 & 0.038 & 0.529 & 0.129 & 0.063 & 0.161 \\
\hline & \begin{tabular}{|l|} 
primary \\
\end{tabular} & 0.537 & 0.316 & 0.117 & 0.193 & $\begin{array}{ll}0.618 \\
\end{array}$ & 0.345 & 0.511 & 0.556 & $\begin{array}{ll}0.566 \\
\end{array}$ & 0.434 & 0.546 & 0.391 & 0.419 & 0.763 & 0.457 \\
\hline & tertiary & 0.107 & 0.235 & 0.243 & 0.250 & 0.171 & 0.302 & 0.266 & 0.232 & 0.122 & 0.147 & 0.070 & 0.186 & 0.244 & 0.088 & 0.322 \\
\hline & unemployed & 0.013 & 0.027 & 0.043 & 0.036 & 0.024 & 0.026 & 0.040 & 0.049 & 0.020 & 0.024 & 0.107 & 0.011 & 0.011 & 0.016 & 0.020 \\
\hline & self employed & 0.084 & 0.070 & 0.071 & 0.071 & 0.097 & 0.082 & 0.024 & 0.083 & 0.166 & 0.105 & 0.173 & 0.049 & 0.067 & 0.105 & 0.083 \\
\hline & recipient of social benefits & 0.093 & 0.095 & 0.140 & 0.110 & 0.047 & 0.124 & 0.112 & 0.245 & 0.101 & 0.075 & 0.165 & 0.066 & 0.102 & 0.081 & 0.091 \\
\hline & poorest quartile & 0.188 & 0.285 & 0.230 & 0.140 & 0.378 & 0.286 & 0.387 & 0.290 & 0.514 & 0.292 & 0.422 & 0.058 & 0.207 & 0.546 & 0.206 \\
\hline \multirow{7}{*}{ 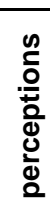 } & wages down & 0.362 & 0.287 & 0.372 & 0.206 & 0.375 & 0.415 & 0.461 & 0.364 & 0.818 & 0.401 & 0.342 & 0.368 & 0.216 & 0.582 & 0.156 \\
\hline & bad for poor & 0.501 & 0.447 & 0.555 & 0.359 & 0.533 & 0.507 & 0.539 & 0.514 & 0.814 & 0.515 & 0.408 & 0.341 & 0.388 & 0.636 & 0.236 \\
\hline & fill jobs & 0.699 & 0.594 & 0.540 & 0.652 & 0.687 & 0.540 & 0.746 & 0.551 & 0.564 & 0.771 & 0.772 & 0.813 & 0.546 & 0.647 & 0.649 \\
\hline & take jobs away & 0.341 & 0.418 & 0.452 & 0.141 & 0.352 & 0.288 & 0.308 & 0.414 & 0.750 & 0.465 & 0.347 & 0.227 & 0.205 & 0.545 & 0.110 \\
\hline & take more out & 0.430 & 0.533 & 0.528 & 0.539 & 0.373 & 0.536 & 0.400 & 0.574 & 0.684 & 0.622 & 0.280 & 0.355 & 0.467 & 0.262 & 0.410 \\
\hline & undermine culture & 0.233 & 0.225 & 0.162 & 0.242 & 0.192 & 0.046 & 0.331 & 0.334 & 0.623 & 0.295 & 0.305 & 0.106 & 0.196 & 0.302 & 0.093 \\
\hline & \begin{tabular}{|l} 
worsen crime \\
\end{tabular} & 0.658 & 0.750 & 0.758 & 0.707 & 0.727 & 0.721 & 0.610 & 0.612 & 0.876 & 0.457 & 0.624 & 0.684 & 0.815 & 0.737 & 0.705 \\
\hline
\end{tabular}


Table 4.1: Estimation results for the four attitude measures

\begin{tabular}{|c|c|c|c|c|c|c|c|}
\hline \multirow{3}{*}{ age } & \multicolumn{4}{|c|}{ Logit: socioeconomic variables } & \multicolumn{3}{|c|}{ Logit: socioeconomic + perceptions } \\
\hline & $A_{\text {poor euro }}$ & $A_{\text {poor noneuro 2002 }}$ & $A_{\text {poor noneuro 2004 }}$ & $A_{\text {relative euro }}$ & $A_{\text {poor euro }}$ & $A_{\text {poor noneuro 2002 }}$ & $A_{\text {relative euro }}$ \\
\hline & $\begin{array}{r}0.0015 \\
\end{array}$ & $\begin{array}{r}-0.0049 \\
\end{array}$ & 0.0078 & $\begin{array}{l}0.0025 \\
\end{array}$ & \begin{tabular}{|l|l|}
-0.0050 \\
\end{tabular} & -0.0127 & \\
\hline & $(0.27)$ & $(-0.90)$ & $(1.65)^{\star}$ & \begin{tabular}{l|l}
$(0.36)$ & 1
\end{tabular} & $(-0.85)$ & $(-2.14)^{\star \star}$ & $(-0.28)$ \\
\hline \multirow[t]{2}{*}{ age squared } & 0.0001 & 0.0002 & 0.0001 & $\begin{array}{l}0.0001 \\
\end{array}$ & $\begin{array}{l}0.0001 \\
\end{array}$ & 0.0002 & 0.0001 \\
\hline & $(1.46)$ & $(3-01)^{\star \star \star}$ & $(1.20)$ & \begin{tabular}{|l|l}
$(1.63)$ & \\
\end{tabular} & $(2.13)^{\star \star}$ & $(3.79)^{\star \star \star}$ & $(1.99)^{\star \star}$ \\
\hline \multirow{2}{*}{ male } & -0.0247 & -0.0143 & -0.0313 & 0.2188 & -0.0772 & -0.0660 & 0.1990 \\
\hline & $(-0.77)$ & $(-0.45)$ & $(-1.10)$ & \begin{tabular}{|l|l}
$(5.36)^{\star \star \star}$ & \\
\end{tabular} & $(-2.23)^{\star \star}$ & $(-1.92)^{\star}$ & $(4.82)^{\star \star \star}$ \\
\hline \multirow[t]{2}{*}{ urban } & \begin{tabular}{|r|}
-0.0882 \\
\end{tabular} & -0.1795 & -0.1874 & 0.1169 & $\begin{array}{r}-0.0470 \\
\end{array}$ & -0.1493 & $\begin{array}{l}0.1467 \\
\end{array}$ \\
\hline & $(-2.51)^{\star \star}$ & $(-5.18)^{\star \star \star}$ & $(-6.11)^{\star \star \star}$ & \begin{tabular}{|l|l}
$(2.66)^{\star \star \star}$ & 1
\end{tabular} & $(-1.23)$ & $(-3.94)^{\star \star \star}$ & $(3.30)^{\star \star \star}$ \\
\hline \multirow[t]{2}{*}{ immigrant } & $\begin{array}{r}-0.5350 \\
\end{array}$ & -0.4398 & $\begin{array}{r}-0.4081 \\
\end{array}$ & 0.0858 & -0.3254 & -0.2205 & 0.2034 \\
\hline & $(-11.03)^{\star \star \star}$ & $(-9.40)^{\star \star \star}$ & $(-10.11)^{\star \star \star}$ & \begin{tabular}{|l|l}
$(1.47)$ & \\
\end{tabular} & $(-6.26)^{\star \star \star}$ & $(-4.36)^{\star \star \star \star}$ & $(3.42)^{\star \star \star}$ \\
\hline \multirow[t]{2}{*}{ primary } & \begin{tabular}{|r|}
0.3411 \\
\end{tabular} & 0.3502 & 0.2664 & -0.0360 & \begin{tabular}{|l|l|}
0.1840 \\
\end{tabular} & 0.1928 & -0.1239 \\
\hline & \begin{tabular}{|l|}
$(8.55)^{\star \star \star}$ \\
\end{tabular} & $(8.85)^{\star \star \star}$ & $(7.31)^{\star \star \star}$ & \begin{tabular}{|l|l}
$(-0.71)$ &
\end{tabular} & $(4.23)^{\star \star \star}$ & $(4.43)^{\star \star \star}$ & $(-2.38)^{\star \star}$ \\
\hline \multirow[t]{2}{*}{ tertiary } & $\begin{array}{r}-0.6674 \\
\end{array}$ & -0.5933 & -0.7240 & \begin{tabular}{|l|}
-0.3668 \\
\end{tabular} & \begin{tabular}{|l|}
-0.3901 \\
\end{tabular} & -0.3003 & -0.2119 \\
\hline & $(-14.58)^{\star \star \star}$ & $(-13.49)^{\star \star \star}$ & $(-18.39)^{\star \star \star}$ & \begin{tabular}{|l|l|}
$(-6.31)^{\star \star \star}$ &
\end{tabular} & $(-7.90)^{\star \star \star}$ & $(-6.27)^{\star \star \star}$ & $(-3.57)^{\star \star \star}$ \\
\hline \multirow[t]{2}{*}{ unemployed } & $\begin{array}{r}0.3514 \\
\end{array}$ & 0.3052 & 0.2183 & $\begin{array}{l}0.3037 \\
\end{array}$ & 0.2317 & 0.1794 & 0.2291 \\
\hline & $(5.57)^{\star \star \star}$ & $(4.86)^{\star \star \star}$ & $(1.94)^{*}$ & $(3.88)^{\star \star \star}$ & $(3.39)^{\star \star \star}$ & $(2.61)^{\star \star \star}$ & $(2.88)^{\star \star \star}$ \\
\hline \multirow[t]{2}{*}{ self employed } & 0.0046 & -0.0351 & 0.0868 & 0.1684 & \begin{tabular}{|l|}
0.0293 \\
\end{tabular} & -0.0242 & 0.1792 \\
\hline & $(0.08)$ & $(-0.61)$ & $(1.50)$ & \begin{tabular}{|l|l}
$(2.38)^{\star \star}$ & \\
\end{tabular} & $\begin{array}{ll}(0.46) \\
\end{array}$ & $(-0.38)^{\star}$ & $(2.50)^{\star \star}$ \\
\hline \multirow{4}{*}{$\begin{array}{l}\text { recipient of social benefits } \\
\text { poorest quartile }\end{array}$} & -0.0302 & -0.0058 & -0.0635 & $\begin{array}{l}-0.0879 \\
\end{array}$ & \begin{tabular}{|l|}
-0.0505 \\
\end{tabular} & -0.0270 & $\begin{array}{r}-0.0932 \\
\end{array}$ \\
\hline & $(-0.54)$ & $(-0.10)$ & $(-0.95)$ & \begin{tabular}{|l|l}
$(-1.27)$ & \\
\end{tabular} & $(-0.84)$ & $(-0.45)$ & $(-1.34)$ \\
\hline & 0.1662 & 0.1077 & 0.0241 & \begin{tabular}{|l|}
-0.0575 \\
\end{tabular} & \begin{tabular}{|l|}
0.1411 \\
\end{tabular} & 0.0730 & \begin{tabular}{|c|}
-0.0795 \\
\end{tabular} \\
\hline & $(4.58)^{\star \star \star}$ & $(2.99)^{\star \star \star}$ & $(0.70)$ & \begin{tabular}{|l|l|}
$(-1.23)$ & \\
\end{tabular} & $(3.58)^{\star \star \star}$ & $(1.85)^{\star}$ & $(-1.68)^{*}$ \\
\hline \multirow[t]{2}{*}{ wages down } & & & & & 0.4451 & 0.4279 & 0.2212 \\
\hline & & & & & $(11.62)^{\star \star \star}$ & $(11.15)^{\star \star \star}$ & $(4.76)^{\star \star \star \star}$ \\
\hline \multirow[t]{2}{*}{ bad for poor } & & & & & 0.4957 & 0.5479 & 0.2955 \\
\hline & & & & & $(13.04)^{\star \star \star}$ & $(14.62)^{\star \star \star}$ & $(6.18)^{\star \star \star}$ \\
\hline \multirow[t]{2}{*}{ fill jobs } & & & & & $\begin{array}{r}-0.4507 \\
\end{array}$ & -0.4329 & -0.0836 \\
\hline & & & & & $(-12.46)^{\star \star \star}$ & $(-11.97)^{\star \star \star}$ & $(-1.94)^{\star}$ \\
\hline \multirow[t]{2}{*}{ take jobs away } & & & & & $\begin{array}{l}0.2496 \\
\end{array}$ & 0.2290 & 0.0287 \\
\hline & & & & & $(6.45)^{\star \star \star}$ & $(5.91)^{\star \star \star}$ & $(0.61)$ \\
\hline \multirow[t]{2}{*}{ take $m$} & & & & & 0.4061 & 0.4136 & 0.1304 \\
\hline & & & & & $(10.70)^{\star \star \star}$ & $\mid(10.98)^{\star \star \star}$ & $(2.78)^{\star \star \star}$ \\
\hline \multirow[t]{2}{*}{ undermine culture } & & & & & 0.8108 & 0.9116 & 0.3664 \\
\hline & & & & & \begin{tabular}{|l|}
$(19.47)^{\star \star \star}$ \\
\end{tabular} & $(21.30)^{\star \star \star}$ & $(7.54)^{\star \star \star}$ \\
\hline \multirow[t]{2}{*}{ worsen crime } & & & & & 0.4819 & 0.5082 & 0.3226 \\
\hline & & & & & $(11.88)^{\star \star \star}$ & $(12.86)^{\star \star \star}$ & $(6.25)^{\star \star \star}$ \\
\hline \multirow[t]{2}{*}{ constant } & -0.7064 & -0.3544 & -0.0085 & \begin{tabular}{|l|}
-2.0118 \\
\end{tabular} & \begin{tabular}{|l|}
-1.6897 \\
\end{tabular} & -1.3325 & -2.5364 \\
\hline & $(-5.27)^{\star \star \star}$ & $(-2.67)^{\star \star \star}$ & $(-0.07)$ & $(-11.55)^{\star \star \star}$ & $(-11.14)^{\star \star \star}$ & $(-8.83)^{\star \star \star \star}$ & $(-13.77)^{\star \star \star}$ \\
\hline \multirow{4}{*}{$\begin{array}{l}\text { Country dummies } \\
\text { Sample size } \\
\text { Pseudo R2 } \\
\text { Log likelihood }\end{array}$} & \begin{tabular}{|l|} 
Included \\
\end{tabular} & Included & Included & Included & Included & Included & \begin{tabular}{|l|l|} 
Included \\
\end{tabular} \\
\hline & 18717 & 18678 & 22439 & 18576 & 18717 & 18678 & 18576 \\
\hline & 0.0752 & 0.0712 & 0.0707 & \begin{tabular}{l|}
0.0191 \\
\end{tabular} & 0.1845 & 0.1887 & 0.0431 \\
\hline & -11767.84 & -11989.01 & -14403.43 & -8222.75 & -10377.75 & -10472.36 & -8021.74 \\
\hline
\end{tabular}


Table 5.1 Decompositions of the four attitude measures

\begin{tabular}{|c|c|c|c|c|c|c|c|}
\hline \multirow[t]{2}{*}{$A_{\text {poor_euro }}$} & \multirow{2}{*}{$\begin{array}{c}\text { Total } \\
\text { deviation }\end{array}$} & \multicolumn{2}{|c|}{ Socioeconomic } & \multicolumn{2}{|c|}{ Perceptions } & \multicolumn{2}{|c|}{ Socio+perceptions } \\
\hline & & $\operatorname{diff} X^{\prime} s$ & diff coefficients & $\operatorname{diff} X ' s$ & diff coefficients & diff X's & diff coefficients \\
\hline AT & 0.1970 & -0.0232 & 0.2202 & -0.0248 & 0.2218 & -0.0336 & 0.2306 \\
\hline $\mathrm{BE}$ & -0.0382 & -0.0101 & -0.0281 & -0.0079 & -0.0302 & -0.0111 & -0.0271 \\
\hline$\overline{D E}$ & -0.0602 & -0.0359 & -0.0243 & 0.0121 & -0.0723 & -0.0019 & -0.0583 \\
\hline$\overline{D K}$ & 0.0327 & -0.0234 & 0.0562 & -0.0507 & 0.0834 & -0.0552 & 0.0879 \\
\hline ES & 0.1043 & 0.0478 & 0.0566 & -0.0257 & 0.1301 & 0.0048 & 0.0995 \\
\hline $\mathrm{FI}$ & 0.1556 & -0.0058 & 0.1614 & -0.0290 & 0.1847 & -0.0240 & 0.1796 \\
\hline FR & -0.0034 & -0.0072 & 0.0038 & -0.0036 & 0.0002 & -0.0065 & 0.0031 \\
\hline GB & 0.0374 & -0.0036 & 0.0410 & 0.0251 & 0.0123 & 0.0223 & 0.0151 \\
\hline GR & 0.4076 & 0.0302 & 0.3774 & 0.2207 & 0.1870 & 0.2226 & 0.1850 \\
\hline IE & -0.1126 & 0.0154 & -0.1280 & -0.0104 & -0.1022 & 0.0004 & -0.1129 \\
\hline IT & -0.0831 & 0.0438 & -0.1269 & -0.0481 & -0.0350 & -0.0256 & -0.0576 \\
\hline LU & 0.0683 & -0.0780 & 0.1463 & -0.0937 & 0.1620 & -0.1318 & 0.2002 \\
\hline $\mathrm{NL}$ & -0.0073 & -0.0109 & 0.0036 & $\begin{array}{l}-0.0377 \\
\end{array}$ & 0.0304 & -0.0365 & 0.0292 \\
\hline PT & 0.1920 & 0.0638 & 0.1282 & 0.0414 & 0.1506 & 0.0726 & 0.1194 \\
\hline SE & -0.2950 & -0.0243 & -0.2707 & -0.1130 & -0.1820 & -0.1136 & -0.1814 \\
\hline Std. Deviation & 0.1631 & & 0.1569 & & 0.1215 & & 0.1231 \\
\hline
\end{tabular}

\begin{tabular}{|c|c|c|c|c|c|c|c|}
\hline \multirow[t]{2}{*}{$A_{\text {poor_noneuro_2002 }}$} & \multirow{2}{*}{$\begin{array}{c}\text { Total } \\
\text { deviation }\end{array}$} & \multicolumn{2}{|c|}{ Socioeconomic } & \multicolumn{2}{|c|}{ Perceptions } & \multicolumn{2}{|c|}{ Socio+perceptions } \\
\hline & & diff X's & diff coefficients & diff X's & diff coefficients & diff X's & diff coefficients \\
\hline AT & 0.1853 & -0.0209 & 0.2062 & -0.0241 & 0.2094 & -0.0392 & 0.2245 \\
\hline $\mathrm{BE}$ & -0.0351 & -0.0047 & -0.0305 & -0.0062 & -0.0289 & -0.0113 & -0.0239 \\
\hline $\mathrm{DE}$ & -0.0483 & -0.0318 & -0.0165 & 0.0130 & -0.0614 & -0.0030 & -0.0453 \\
\hline DK & 0.0912 & -0.0189 & 0.1102 & -0.0480 & 0.1392 & -0.0543 & 0.1455 \\
\hline ES & 0.0612 & 0.0448 & 0.0164 & -0.0248 & 0.0860 & 0.0009 & 0.0603 \\
\hline $\mathrm{FI}$ & 0.1650 & -0.0029 & 0.1678 & -0.0284 & 0.1934 & -0.0247 & 0.1896 \\
\hline FR & 0.0084 & -0.0062 & 0.0146 & -0.0014 & 0.0098 & -0.0081 & 0.0166 \\
\hline GB & 0.0319 & 0.0026 & 0.0293 & 0.0251 & 0.0068 & 0.0239 & 0.0080 \\
\hline GR & 0.3871 & 0.0230 & 0.3641 & 0.2207 & 0.1664 & 0.0115 & 0.3756 \\
\hline $\mathrm{IE}$ & -0.1102 & 0.0120 & -0.1222 & -0.0105 & -0.0997 & -0.0073 & -0.1029 \\
\hline IT & -0.0776 & 0.0483 & -0.1258 & -0.0475 & -0.0301 & -0.0289 & -0.0487 \\
\hline LU & 0.0731 & -0.0568 & 0.1300 & -0.0944 & 0.1675 & -0.1265 & 0.1996 \\
\hline $\mathrm{NL}$ & -0.0296 & -0.0058 & -0.0238 & -0.0349 & 0.0053 & -0.0342 & 0.0046 \\
\hline $\mathrm{PT}$ & 0.1632 & 0.0576 & 0.1057 & 0.0425 & 0.1207 & 0.0621 & 0.1011 \\
\hline SE & -0.3213 & -0.0185 & -0.3029 & -0.1150 & -0.2063 & -0.1136 & -0.2077 \\
\hline Std. Deviation & 0.1610 & & 0.1583 & & 0.1213 & & 0.1483 \\
\hline
\end{tabular}


Part C

\begin{tabular}{|c|c|c|c|}
\hline \multirow[t]{2}{*}{ A $_{\text {poor_noneuro_2004 }}$} & \multirow{2}{*}{$\begin{array}{c}\text { Total } \\
\text { deviation }\end{array}$} & \multicolumn{2}{|c|}{ Socioeconomic } \\
\hline & & diff X's & diff coefficients \\
\hline$\overline{\text { AT }}$ & -0.0140 & -0.0718 & 0.0578 \\
\hline$\overline{B E}$ & -0.0238 & -0.0798 & 0.0560 \\
\hline$\overline{\mathrm{DE}}$ & 0.0255 & -0.0902 & 0.1157 \\
\hline DK & 0.0731 & -0.0855 & 0.1585 \\
\hline ES & 0.1210 & -0.0709 & 0.1919 \\
\hline $\mathrm{FI}$ & 0.1492 & -0.0780 & 0.2273 \\
\hline $\mathrm{FR}$ & 0.0046 & -0.0748 & 0.0793 \\
\hline$\overline{G B}$ & -0.0249 & -0.0819 & 0.0570 \\
\hline GR & 0.2880 & -0.0722 & 0.3602 \\
\hline IE & -0.1726 & -0.0763 & -0.0962 \\
\hline$\overline{L U}$ & -0.0141 & -0.0863 & 0.0722 \\
\hline $\mathrm{NL}$ & -0.0444 & -0.0764 & 0.0319 \\
\hline PT & 0.1691 & -0.0648 & 0.2338 \\
\hline SE & -0.3392 & -0.0754 & -0.2637 \\
\hline Std. Deviation & 0.1519 & & 0.1507 \\
\hline
\end{tabular}

Part D

\begin{tabular}{|c|c|c|c|c|c|c|c|}
\hline \multirow[t]{2}{*}{$\overline{A_{\text {relative_euro }}}$} & \multirow{2}{*}{$\begin{array}{c}\text { Total } \\
\text { deviation }\end{array}$} & \multicolumn{2}{|c|}{ Socioeconomic } & \multicolumn{2}{|c|}{ Perceptions } & \multicolumn{2}{|c|}{ Socio+perceptions } \\
\hline & & diff $X ' s$ & diff coefficients & $\operatorname{diff} X^{\prime} s$ & diff coefficients & diff X's & diff coefficients \\
\hline AT & 0.0215 & -0.0050 & 0.0266 & -0.0078 & 0.0294 & -0.0070 & 0.0285 \\
\hline $\mathrm{BE}$ & 0.0101 & -0.0063 & 0.0163 & -0.0069 & 0.0169 & -0.0090 & 0.0191 \\
\hline$\overline{\mathrm{DE}}$ & 0.0162 & -0.0028 & 0.0191 & -0.0022 & 0.0185 & 0.0040 & 0.0122 \\
\hline$\overline{\mathrm{DK}}$ & 0.1032 & -0.0002 & 0.1034 & -0.0148 & 0.1180 & -0.0097 & 0.1129 \\
\hline ES & -0.0297 & -0.0076 & -0.0221 & -0.0069 & -0.0228 & -0.0181 & -0.0116 \\
\hline $\mathrm{FI}$ & 0.0297 & -0.0101 & 0.0399 & -0.0128 & 0.0425 & -0.0185 & 0.0482 \\
\hline $\mathrm{FR}$ & -0.0136 & -0.0159 & 0.0023 & 0.0009 & -0.0145 & -0.0122 & -0.0014 \\
\hline GB & -0.0009 & -0.0096 & 0.0087 & 0.0013 & -0.0022 & -0.0050 & 0.0041 \\
\hline GR & 0.0819 & 0.0030 & 0.0789 & 0.0637 & 0.0191 & 0.0664 & 0.0155 \\
\hline $\mathrm{IE}$ & -0.0295 & -0.0077 & -0.0218 & -0.0081 & -0.0213 & -0.0141 & -0.0154 \\
\hline IT & 0.0134 & -0.0060 & 0.0194 & -0.0132 & 0.0267 & -0.0224 & 0.0358 \\
\hline $\mathrm{LU}$ & -0.0606 & -0.0076 & -0.0530 & -0.0243 & -0.0373 & -0.0216 & -0.0391 \\
\hline $\mathrm{NL}$ & -0.0616 & -0.0112 & -0.0505 & -0.0121 & -0.0495 & -0.0194 & -0.0422 \\
\hline PT & -0.0033 & -0.0069 & 0.0036 & 0.0112 & -0.0144 & -0.0030 & -0.0003 \\
\hline SE & -0.0806 & -0.0086 & -0.0720 & -0.0321 & -0.0486 & -0.0346 & -0.0461 \\
\hline Std. Deviation & 0.0501 & & 0.0472 & & 0.0428 & & 0.0403 \\
\hline
\end{tabular}

